\title{
Identification of foraging dives in free-ranging Weddell seals Leptonychotes weddellii: confirmation using video records
}

\author{
K. M. Madden ${ }^{1, *}$, L. A. Fuiman ${ }^{1}$, T. M. Williams ${ }^{2}$, R. W. Davis ${ }^{3}$ \\ ${ }^{1}$ Department of Marine Science, University of Texas at Austin, Marine Science Institute, 750 Channel View Drive, \\ Port Aransas, Texas 78373, USA \\ ${ }^{2}$ Department of Marine Biology, Texas A\&M University, 5007 Avenue U, Galveston, Texas 77553, USA \\ ${ }^{3}$ Department of Biology and Institute of Marine Science, EMS-A316, University of California, Santa Cruz, \\ California 95064, USA
}

\begin{abstract}
Understanding foraging behavior is important for addressing ecological questions about air-breathing marine vertebrates. However, the inability to directly observe them underwater has made it difficult to classify and understand their foraging behaviors. We equipped 8 free-ranging, adult Weddell seals with animal-borne video and data recorders (VDRs) to monitor their underwater behavior. Eighteen dive descriptors summarizing the duration, depth, speed, stroking frequency, gliding, and energetic cost of 234 dives were calculated. Dive descriptors were included in nonhierarchical cluster analyses that identified 5 groups of dives. Eight of the 18 dive descriptors contributed strongly to the discrimination between dive groups. Presence of prey on the video record confirmed Groups 1, 4, and 5 as foraging dives. Group 1 dives were deep and exceeded the estimated aerobic dive limit, while Group 4 dives were also deep but probably remained aerobic. Group 5 dives were shallow and aerobic. Comparisons with prior classifications showed that deep aerobic dives were similar in depth and duration to foraging dives identified in previous studies, but shallow aerobic dives represented a previously undescribed foraging category. Deep anaerobic dives also differed from previous classifications and were not indicative of benthic foraging, as was previously thought. The proportion of successful foraging dives (at least on prey encounter observed on video) varied among the groups and among locations with different bathymetry. The distribution of foraging dive types also varied among these locations. These results will help characterize foraging activity of Weddell seals and provide a better understanding of the energetic costs and foraging strategies of diving marine predators.
\end{abstract}

KEY WORDS: Marine mammal - Behavior - Classification · Silverfish · Geographical variation · McMurdo Sound

Resale or republication not permitted without written consent of the publisher

\section{INTRODUCTION}

The diving behavior of air-breathing marine vertebrates consists of a series of movements and events that can be divided into discrete units for behavioral analysis. In most cases, a repertoire of stereotyped movements exists that can be easily distinguished (i.e. modal action patterns), although some variability may exist within these characteristic behaviors (Hinde
1982). The types of behavioral categories defined, particularly the extent to which they are specific rather than general, depends on the scope of the information that is required (Martin \& Bateson 1993). Examples of several broad, general categories include: reproduction, foraging, communication, and traveling. When the information being sought is more specific, it becomes necessary to divide these general behavioral acts into their component parts (Martin \& Bateson 
1993, Lehner 1996). For example, foraging behavior can be subdivided into search, pursuit, and handling. The capacity for identifying behavioral categories, specific or general, usually depends on the extent to which a researcher can observe the animal (Hinde 1982).

For many years, the challenges associated with monitoring the underwater excursions of free-ranging diving mammals have made it difficult to classify their behavior with certainty (Davis et al. 2003, Fuiman et al. 2007). Methods such as SCUBA, fixed-location cameras, remotely operated vehicles, and manned submersibles provide only short glimpses of highly mobile animals (Davis et al. 1999, Kooyman 2004, Block 2005). New developments in bio-logging technology (i.e. the use of animal-borne instruments to gather data) have helped overcome some of these challenges. The use of time-depth recorders and satellite-linked time-depth recorders to collect information about the depth, duration, and location of dives has greatly increased our knowledge of the diving behavior and movements of large marine vertebrates (Fedak et al. 2002, Kooyman 2004, Block 2005). Recent developments in acoustic tracking (Wartzok et al. 1992, Harcourt et al. 2000, Simpkins et al. 2001), dead reckoning (Wilson et al. 1991, Davis et al. 1999), geomagnetic and acceleration recorders (Mitani et al. 2003, 2004), and digital acoustic recording tags (Johnson \& Tyack 2003) have allowed researchers to go beyond recording just time and depth of diving animals, to recording 3-dimensional movements and the animal's body orientation.

These techniques have provided many new insights into the behavior and ecology of diving animals, but none enable direct observation of an animal's behavior at depth. Researchers have frequently used time, depth, and swimming speed data to classify dives and to assign ecological functions such as foraging, exploration, and transiting (e.g. Hindell et al. 1991, LeBoeuf et al. 1992, Crocker et al. 1997). Identification of foraging dives is particularly important because of the potential benefits that correct conclusions could have on our understanding of predator-prey interactions, energetic efficiency, and optimal foraging strategies. Some researchers have added additional sensors that record stomach temperature, jaw movements, and vocalizations, in attempts to confirm prey encounters (e.g. Lesage et al. 1999, Plötz et al. 2001, Johnson et al. 2004, Madsen et al. 2005), while other researchers have used animal-borne still and video cameras to directly confirm underwater feeding events (e.g. Marshall 1998, Davis et al. 1999, Fuiman et al. 2002, Hooker et al. 2002, Sato et al. 2002, Watanabe et al. 2003). These methods have already shown that some of the previous inferences about foraging behavior were incorrect (Lesage et al. 1999, Davis et al. 2003).
The diving habits of the Weddell seal Leptonychotes weddellii have been well studied using time-depth recorders and satellite-linked, time-depth recorders (Kooyman 1981, Castellini et al. 1992, Testa 1994), acoustic tracking (Harcourt et al. 2000, Hindell et al. 2002), dead reckoners (Davis et al. 1999, 2003), and geomagnetic and acceleration recorders (Mitani et al. 2003, 2004). These seals are highly adapted for hunting in the cold, dark, ice-covered waters of Antarctica (Kooyman 1981, Castellini et al. 1992). Their holebreathing strategy and ability to dive to extreme depths allows them to hunt in both the pelagic and benthic environments of the Antarctic continental shelf (Lake et al. 2003). The diet of Weddell seals in McMurdo Sound has been shown to vary little and consists primarily of small nototheniid fishes such as silverfish (Pleuragramma antarcticum) and Trematomus spp. (Castellini et al. 1992, Burns et al. 1998, Davis et al. 1999). However, other types of prey are available and the seals are known to feed occasionally on Antarctic toothfish Dissostichus mawsoni, Gymnodraco spp., icefishes, mysids, decapod and amphipod crustaceans, octopus, and squid (Dearborn 1965, Testa et al. 1985, Davis et al. 1999).

Two previous studies have classified the diving behavior of free-ranging Weddell seals using data collected with time-depth recorders. Kooyman (1968) used a subjective approach to categorize diving behavior and found 3 distinct dive types. Of these, Pattern III dives were assumed to involve foraging, since they were numerous, reached 300 to $400 \mathrm{~m}$, lasted 8 to $14 \mathrm{~min}$, and contained steep rates of ascent and descent. Schreer \& Testa (1996) used a multivariate classification method to identify 6 distinct dive types. Two of these were believed to be foraging dives. The first group, termed mid-water foraging dives, was characterized by deep time-depth profiles with multiple small ascents and descents along the bottom of the dive. The second group also had deep time-depth profiles but without multiple, small ascents and descents along the bottom part of the dive. These were assumed to be benthic foraging dives. More recently, Davis et al. (2003) classified Weddell seal diving behavior at an isolated hole using an animal-borne video and data recorder (VDR) that enabled the calculation (dead reckoning) of 3-dimensional movements. This was the first classification of marine mammal diving behavior to use video observations of prey encounters to confirm foraging events at an isolated hole. Four types of dives were identified using a multivariate classification method and the presence of prey on the video record revealed that foraging occurred during Type 1 dives. Type 1 dives were similar to the presumed foraging dives from 2 previous classification studies. However, Type 1 dives had a wider depth and duration range 
than the foraging dives of Kooyman (1968) and several Type 1 dives were misclassified into non-foraging groups using the criteria described by Schreer \& Testa (1996). The isolated-hole protocol used by Davis et al. (2003) restricted the seals to a single breathing hole and prevented them from interacting with other seals. It is likely that this protocol would limit the variety of dive types free-ranging seals would use for foraging.

Seals that are not restricted to a single breathing hole (i.e. free-ranging) are capable of traveling to, and foraging in, areas with different bathymetry, prey type, prey availability, and number of conspecifics. Therefore, where an animal chooses to forage could affect its foraging behavior (Boyd et al. 2002, Lake et al. 2003, Tremblay \& Cherel 2000, Hume et al. 2004). For example, Mitani et al. (2004) found that Weddell seals foraging at 2 locations in McMurdo Sound had to travel different distances in order to reach mid-water prey (Antarctic silverfish). Although seals foraged in areas of similar prey abundance (Watanabe et al. 2003), individuals diving along the coast were forced by the slope of the island to descend at a slower rate and travel farther horizontally than seals over deeper water (Mitani et al. 2004).

In the current study, 13 free-ranging adult Weddell seals were equipped with the same VDRs used by Davis et al. (2003). This allowed us to: (1) compare our results with those from previous studies that were based solely on inferences from depth and time statistics, (2) explore how the foraging behavior of freeranging seals differed from that of individuals diving at an isolated breathing hole, and (3) investigate how foraging behavior varied at different locations within the study area. Our results indicate that there were 5 distinct diving patterns in free-ranging Weddell seals, 3 of which were recognized as foraging dives by the presence of prey on the video record.

\section{MATERIALS AND METHODS}

Animal capture and instrumentation. Eight adult Weddell seals ( 7 non-lactating females, 1 male; body mass $=432.6 \pm 75.6 \mathrm{Kg}[$ mean $\pm \mathrm{SD}]$; standard length $=$ $239.9 \pm 9.0 \mathrm{~cm}$ ) were captured near Ross Island, McMurdo Sound, Antarctica from October to November of 2001 and 2002 (Table 1, Fig. 1). Capture and instrumentation methods have been described by Davis et al. (1999). Briefly, seals were captured on the sea ice using a purse-string net and were transported to a field camp using a specially designed sled. Upon arrival at the field camp, animals were sedated (with ketamine and diazepam), weighed, and measured. After cleaning the fur with acetone, we glued a piece of thin neoprene rubber (ca. $30 \mathrm{~cm}$ in diameter) to the
Table 1. Leptonychotes weddellii. Sample size (dives with both data and video), capture year, sex, mass, and length of 8 free-ranging Weddell seals instrumented from October to November, 2001 and 2002, in McMurdo Sound, Antarctica

\begin{tabular}{|lrcccc|}
\hline Seal no. & N & Year & Sex & Mass $(\mathrm{kg})$ & Length $(\mathrm{cm})$ \\
\hline 19 & 28 & 2001 & Female & 316.1 & 240.0 \\
20 & 6 & 2001 & Male & 363.4 & 227.0 \\
25 & 60 & 2002 & Female & 391.0 & 231.5 \\
26 & 58 & 2002 & Female & 428.4 & 246.0 \\
27 & 32 & 2002 & Female & 459.2 & 232.0 \\
28 & 13 & 2002 & Female & 466.6 & 245.0 \\
29 & 28 & 2002 & Female & 559.8 & 253.5 \\
31 & 9 & 2002 & Female & 476.0 & 244.0 \\
\hline
\end{tabular}

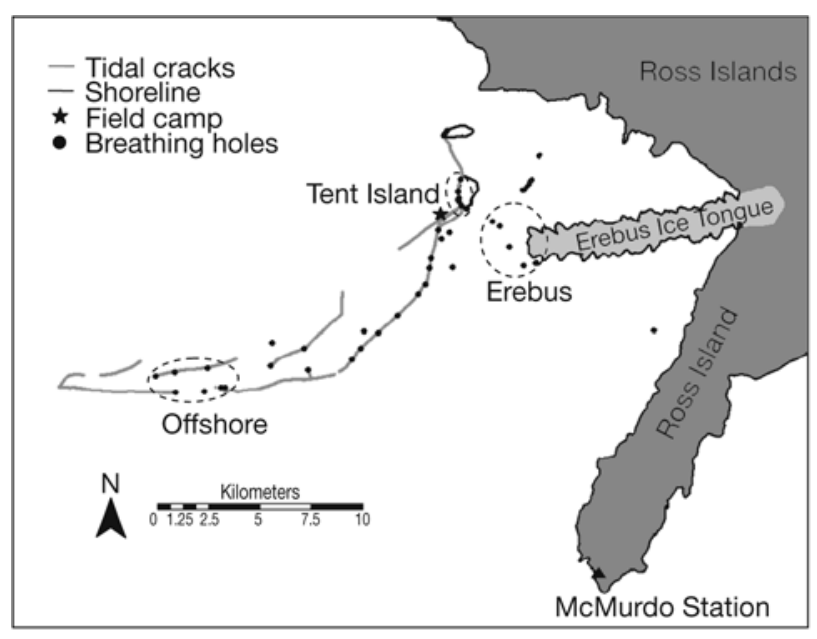

Fig. 1. Study area within McMurdo Sound (primary diving locations circled and labeled) with UTM coordinates listed around perimeter. Seals 19 and 20 dove near the Erebus Ice Tongue, Seals 25-31 dove along the west coast of Tent Island, and Seals 25 and 26 dove at offshore breathing holes located over the deeper waters of McMurdo Sound

seal's back using contact cement. The neoprene rubber provided a secure but flexible attachment for the main housing of the VDR. The main housing $(35 \mathrm{~cm}$ long $\times 13 \mathrm{~cm}$ in diameter) was placed in a molded, non-compressible foam cradle and secured to the neoprene rubber with a hose clamp, Velcro and plastic cable ties. The foam cradle offset the weight of the instruments so the unit was neutrally buoyant in water. The video camera $(6 \mathrm{~cm}$ long $\times 6 \mathrm{~cm}$ in diameter; mounted on the head), compass housing (17 cm long by $5.5 \mathrm{~cm}$ in diameter; placed behind the main housing) and accelerometer $(6 \times 3 \times 2 \mathrm{~cm}$; mounted on the dorsal surface near the base of the tail) were glued to the fur using the same method. A satellite transmitter and 2 VHF radio transmitters were also glued to the fur to enable seals to be relocated once they were released. Each animal was allowed to recover from 
anesthesia for about $18 \mathrm{~h}$ before it was released into a $1.3 \mathrm{~m}$ diameter, man-made breathing hole at the field camp. The field camp was located less than $1 \mathrm{~km}$ from additional breathing holes (Fig. 1). This allowed seals to move throughout the study area and interact with other animals (i.e. seals were free-ranging).

The instruments were typically deployed for 3 to $5 \mathrm{~d}$ before the seals were relocated and had their instruments changed for additional deployments (1 to 6 deployments per seal). When the seals hauled out on the ice, the satellite transmitters provided the seal's location to within one-half $\mathrm{km}$ radius and VHF radio transmitters enabled us to determine the seal's exact location using a receiver and directional antenna. All animal-handling procedures were in accordance with animal use protocols of The University of Texas at Austin and Texas A\&M University.

Video data logger. The self-contained video camera and data logger were designed to record the behavior, swimming performance, 3-dimensional movements, and environment immediately in front of diving animals, and have previously been described by Davis et al. (1999). To summarize, the data logger was contained in a torpedo-shaped, aluminum housing and was designed to record data from several instruments: (1) a low-light sensitive, monochrome video camera, surrounded by an array of near-infrared light-emitting diodes and mounted on the animal's head, (2) a pressure transducer, (3) a water speed sensor (paddle wheel), (4) a gimbaled flux-gate compass, and (5) a small, 1-axis accelerometer placed on the dorsal surface near the base of the seal's tail that recorded lateral sweeps of the posterior half of the body and the hind flippers. Pressure, speed, and bearing were sampled 1 time $\mathrm{s}^{-1}$, and the camera recorded at a rate of 30 frames $\mathrm{s}^{-1}$. The accelerometer was sampled 16 times $\mathrm{s}^{-1}$ and was synchronized with dive depth, time, and video images. Accelerometer output varied as the tail moved from one side to another, stopping momentarily at the end of a stroke before the tail reversed directions. This allowed identification of individual strokes during swimming, as well as periods of no stroking (i.e. gliding). A stroke was equivalent to 1 right-to-left (or left-to-right) movement of the hind flippers. In an earlier study, the accuracy of the accelerometer was tested by comparing output from the accelerometer to simultaneous video recordings of hind flippers during swimming (Williams et al. 2004). The diodes enabled the camera to record images underwater in complete darkness up to a distance of ca. $1 \mathrm{~m}$ and further when additional ambient light was available. The infrared light source $\left(\lambda_{\max }=850 \mathrm{~nm}\right)$ was assumed to be invisible to the seals and their prey (Lavigne et al. 1977); it did not interfere with normal behavior of the seals or their prey. The pressure transducer was calibrated in the laboratory for water depth. The compass was calibrated at the deployment site using the position of the sun, together with GPS location, time, and a navigation computer. The speed sensor was calibrated after each deployment using the method of Blackwell et al. (1999). Although it is difficult to determine with certainty the effect of the equipment on the behavior of the animal, the additional hydrodynamic drag created by the VDR did not result in significant differences in the recovery oxygen consumption for seals diving with the VDR and seals diving with time-depth recorders (Williams et al. 2004). The frontal area of the video camera and data logger occupied $<5.5 \%$ of the frontal area of the seal and was within suggested limits for instrumented swimming animals (Wilson et al. 1986, Culik et al. 1994).

The location of dives was determined by gathering the GPS locations of several breathing holes within the study area using handheld GPS units and placing distinct markers in each hole so they could be identified on the video record and matched to the handheld GPS coordinates. When the seals failed to surface in a marked hole, observations of distinctive underwater features (e.g. continental slope of Tent Island, the Erebus Ice Tongue) on the video record were used to place the seals within a general geographic context.

Identification of dive groups. Data and video were downloaded immediately upon recovery of the instruments. Each video tape was duplicated in VHS format and a time-and-date code was superimposed on the video display to facilitate later analysis. The video tapes were reviewed for scenes of interest (e.g. encounters with prey, visible substrate, hole markers) and used to build a database of prey encounters. Interactions with several different types of prey were documented on the video record (Fig. 2). These included encounters with silverfish Pleuragramma antarcticum, Trematomus spp., bald notothen Pagothenia borchgrevinki, icefish, octopus, krill, and several unidentifiable prey items. The type, number, and time of each prey encountered (i.e. prey located $<1 \mathrm{~m}$ from the seals muzzle but ingestion of prey not always evident) was recorded for each dive. Video and data were gathered from 234 dives (6 to 60 dives per seal). Eighteen variables (Table 2) were computed to describe each dive based on characteristics of time, distance, speed, stroking of the hind flippers, gliding (defined as 3 continuous seconds with no stroking of the flippers), and energetic cost. Energetic cost was calculated for each dive from the equation (Non-Feeding $\mathrm{VO}_{2 \text { rec }}=\mathrm{BMR} r+$ locomotor cost $\left.=\left(9.98 M_{\mathrm{b}}{ }^{-0.25}\right) t+0.04 S_{\text {tot }}\right)$ provided by Williams et al. (2004) for non-feeding Weddell seals. This equation estimates oxygen consumption during a dive from the seal's body mass, duration of the dive, and the number of strokes of the hind flippers. It does 

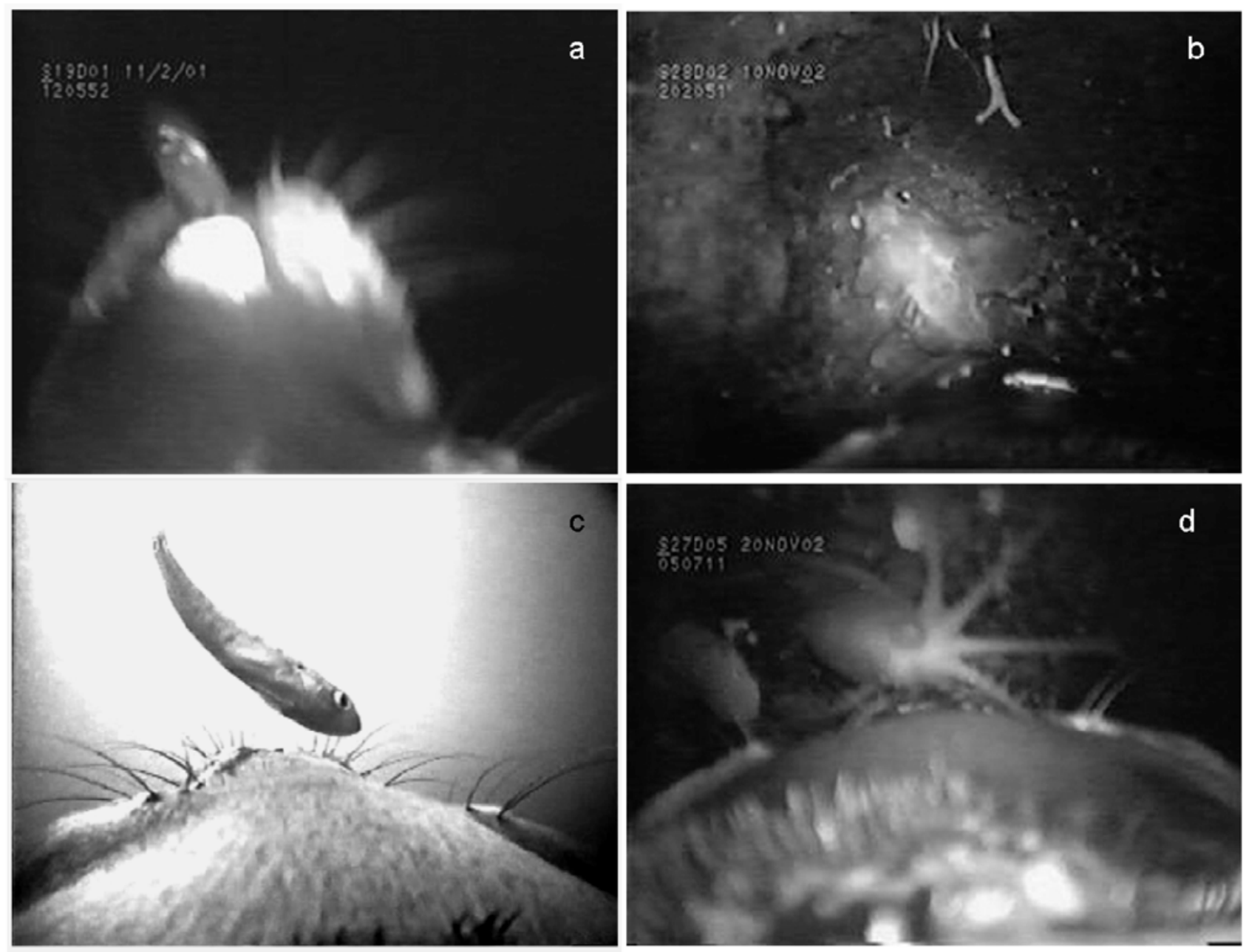

Fig. 2. Leptonychotes weddellii. Images captured from head-mounted video camera. Weddell seals encountered several types of prey while foraging within McMurdo Sound, Antarctica: (a) silverfish Pleuragramma antarcticum caught in midwater, (b) Trematomus spp. encountered on the bottom, (c) bald notothen Pagothenia borchgrevinki encountered near the surface, and (d) octopus encountered on the bottom. The seal's muzzle and eyes are visible in the lower portion of each image

not take into account the added cost associated with processing a meal (i.e. heat increment of feeding), but was chosen because it provided a standard method for calculating energy consumption throughout the entire course of a dive. Energy flux $\left(\mathrm{ml} \mathrm{O}_{2} \mathrm{~min}^{-1} \mathrm{~kg}^{-1}\right)$ was calculated by dividing the total energetic cost $\left(\mathrm{ml} \mathrm{O}_{2}\right.$ $\mathrm{kg}^{-1}$ ) of a dive by dive duration.

Failures of the GPS unit to register a position while the seal was at the surface allowed only 114 dives to be reconstructed in 3-dimensions using standard deadreckoning techniques (Davis et al. 1999). Therefore, in order to maintain a larger sample size, no variables describing the 3-dimensional structure of a dive were included in this analysis. Davis et al. (2003) found that foraging dives of Weddell seals diving from an offshore, isolated hole could easily be distinguished without using 3-dimensional variables. In that study, foraging dives were correctly identified $92 \%$ of the time using dive duration, depth, and speed statistics (Davis et al. 2003).

Dives were grouped based on similarities in duration, depth, speed, stroking of the hind flippers, gliding, and energetic cost using a $k$-means cluster analysis. This non-hierarchical clustering method was chosen because it does not impose relationships upon the groups. All variables were standardized to a mean of 0 and a SD of 1 before applying the clustering procedure. Since $k$-means clustering requires the number of groups be defined a priori and the appropriate number of groups was unknown, 7 cluster analyses were performed specifying a different number of clusters in each, ranging from 2 to 8 clusters. Clusters that contained $<7 \%$ of the total dives $(\mathrm{N}=16)$ were considered outliers, or rare types of diving behavior, and were disregarded. Results of the cluster analysis were then combined with the jack-knifed cross-validation per- 
Table 2. Leptonychotes weddellii. Variables used to describe dives of free-ranging Weddell seals

\begin{tabular}{|c|c|}
\hline Variable & Definition (units) \\
\hline 1. Mean depth (MN_Z) & Mean of all depths recorded during dive (m) \\
\hline 2. Max depth (MX_Z $)$ & Maximum depth recorded during dive (m) \\
\hline 3. Depth variability (Z_CV) & $\begin{array}{l}\text { Variability in depth recorded during dive, expressed as the coefficient of } \\
\text { variation }(\mathrm{CV}=\mathrm{SD} / \mathrm{mean})\end{array}$ \\
\hline 4. Dive duration (DURA_S) & Total time spent in dive (min) \\
\hline 5. Total distance (TOT_DIST) & Total distance traveled along the swimming path during dive (m) \\
\hline 6. Mean speed (MN_SPEED) & Mean speed during dive $\left(\mathrm{m} \mathrm{s}^{-1}\right)$ \\
\hline 7. Max speed (MX_SPEED) & Maximum speed reached during dive $\left(\mathrm{m} \mathrm{s}^{-1}\right)$ \\
\hline 8. Speed variability (SPEED_CV) & Variability in speed during dive, expressed as the coefficient of variation \\
\hline 9. Mean stroking rate (MN_STROKE) & Average strokes per second during dive (strokes $\mathrm{s}^{-1}$ ) \\
\hline 10. Maximum stroking rate (MX_STROKE) & Maximum stroking rate during dive (strokes $\left.\mathrm{s}^{-1}\right)$ \\
\hline 11. Stroking rate variability (STROKE_CV) & $\begin{array}{l}\text { Variability in stroking rate during dive, expressed as the coefficient of } \\
\text { variation }\end{array}$ \\
\hline 12. Total number of strokes (TOT_STROKES) & Total number of strokes during dive (strokes) \\
\hline 13. Total energy (TOT_ENERGY) & $\begin{array}{l}\text { Total amount of energy used during dive }\left(\mathrm{ml} \mathrm{O}_{2} \mathrm{~kg}^{-1}\right) \text {, calculated using } \\
\text { non-feeding equation from Williams et al. }(2004)\end{array}$ \\
\hline 14. Energy rate (ENERGY_RT) & $\begin{array}{l}\text { Total amount of energy used during dive divided by the amount of time } \\
\text { spent in dive }\left(\mathrm{ml} \mathrm{O}_{2} \mathrm{~kg}^{-1} \mathrm{~min}^{-1}\right)\end{array}$ \\
\hline 15. Sum of gliding (SUM_GLIDE) & Total amount of time spent gliding during dive (s) \\
\hline 16. Gliding\% (PCT GLIDE) & Percentage of entire dive spent gliding \\
\hline 17. Time below silverfish depth (SUM_155) & $\begin{array}{l}\text { Amount of time spent below } 155 \mathrm{~m} \text {, the average minimum depth of } \\
\text { silverfish (s) }\end{array}$ \\
\hline 18.\% Dive below silverfish depth (PCT_155) & $\begin{array}{l}\text { Percentage of total dive duration spent below } 155 \mathrm{~m} \text {, the average minimum } \\
\text { depth of silverfish }\end{array}$ \\
\hline
\end{tabular}

centages of a subsequent discriminant analysis to determine the final number of dive clusters. The jackknifed cross-validation procedure avoids bias by allocating samples to their closest group without using that particular sample to help determine the group center (Manly 2005). Discriminant analysis was also used to determine whether the groups were significantly different (Wilks' lambda value) from one another and which variables, or combinations of variables, contributed strongly to the separation. A variable was considered important in the discrimination if the absolute value of the standardized canonical coefficient was high relative to the other variables. The discriminant analysis was conducted using raw values and a forward stepwise procedure with a tolerance level of 0.001 to add variables to the analysis. All statistical analyses were performed with Systat statistical software (version 10.2; Systat Software).

Geographic variability. Diving occurred in 3 distinct geographic regions within McMurdo Sound (Fig. 1) and contingency table analyses were used to determine whether diving behavior varied among these regions. Seals 19 and 20 dove at breathing holes near the Erebus Ice Tongue. Seals 25 through 31 used breathing holes located along the western coast of Tent Island. Seals 25 and 26 traveled away from Ross Island and dove at several offshore breathing holes located over the deeper waters of McMurdo Sound. Observations of the sea floor from the video record showed that bathymetry varied among these locations.
At Tent Island, the sea floor was visible shortly after the seals left the breathing hole, indicating shallow depth along the coastline. When the sea floor was observed at offshore breathing holes and near the Erebus Ice Tongue, it occurred late and deep in a dive, indicating that seals were diving in deeper water away from the coast.

A 2-way contingency table was used to test for independence of the distribution of dive types among the 3 regions (Pearson's chi-square). Expected values for each region (see Table 6) met the requirements of contingency table analysis (all cells with expected frequencies $>5$ ) and all regions could therefore be included in the analysis (Lehner 1996). Standardized deviates were used to characterize departures of the observed values from expected values for each analysis.

\section{RESULTS}

\section{Identification of dive groups}

When 2 to 5 groups were defined, the number of dives allocated to each group exceeded 29. When 6 to 8 groups were specified, there was at least one cluster present with fewer than 16 dives (less than $7 \%$ of the total number of dives). This suggested that a maximum of 5 groups could be defined before the cluster analysis created artificial groupings. This was supported by the jack-knife cross-validation values of the subse- 
quent discriminant analysis. Overall jack-knife classification values ranged from 90 to $97 \%$. When 5 groups were specified the jack-knife classification success was $94 \%$, indicating the presence of uniquely defined groups. The only classification procedure with a higher value was 2 groups (97\%). However, group size data does not support the presence of 2 groups, since additional groups could be defined without cluster size decreasing below $7 \%$ of the total number of dives. When $3,4,6,7$, or 8 groups were specified, jack-knife classification values decreased to $93,91,93,90$, and $90 \%$, respectively.

The discriminant analysis also showed that the 5 groups were significantly different from one another (Wilks' lambda $=0.002, \mathrm{p}<0.001$ ). All 18 dive descriptors were included in the analysis. Jack-knife classification success was high, with only a small number of misclassifications (14) for the 5 dive groups (Table 3). The presence of prey, as recorded on the video tape, was used to determine which of the 5 dive groups were used for foraging. Groups 1, 3, 4, and 5 contained at least 1 dive with a prey encounter (Table 3). Groups 1, 4 , and 5 were assumed to be foraging dives because of the high percentage of prey encounters in each of these groups $(75.0,82.4$, and $20.7 \%$, respectively [Table 3]). Groups 2 and 3 were assumed to be nonforaging dives because of the very low occurrence of prey encounters ( 0.0 and $2.4 \%$, respectively; Table 3 ). Dives in Groups 1, 4, and 5 in which the seal did not encounter prey were considered to be unsuccessful foraging dives.

The 3 groups of foraging dives $(1,4$, and 5) were separated from the 2 non-foraging groups ( 2 and 3 ) primarily by discriminant axis 1 (DA1 [Fig. 3a]). DA1 had the highest discriminatory power with an eigen value of 12.7. Eight variables had high loadings on DA1 and were responsible for the separation along this axis (Fig. 3b, Table 4). Many of the same variables were also responsible for the small amount of separation contributed by DA2 (eigen value of 4.1 [Fig. 3, Table 4]). Dive descriptors characterizing the depth, duration, stroking of the hind flippers, and energetic cost of a dive were important in the separation along DA1 and DA2, but none of the descriptors for speed or gliding contributed to the separation. DA3 and DA4 contributed very little to the overall discrimination of dive groups (eigen values of 2.3 and 1.6, respectively).

\section{Description of dive groups}

Groups 1, 4, and 5 each represented a distinct type of foraging dive. Mean
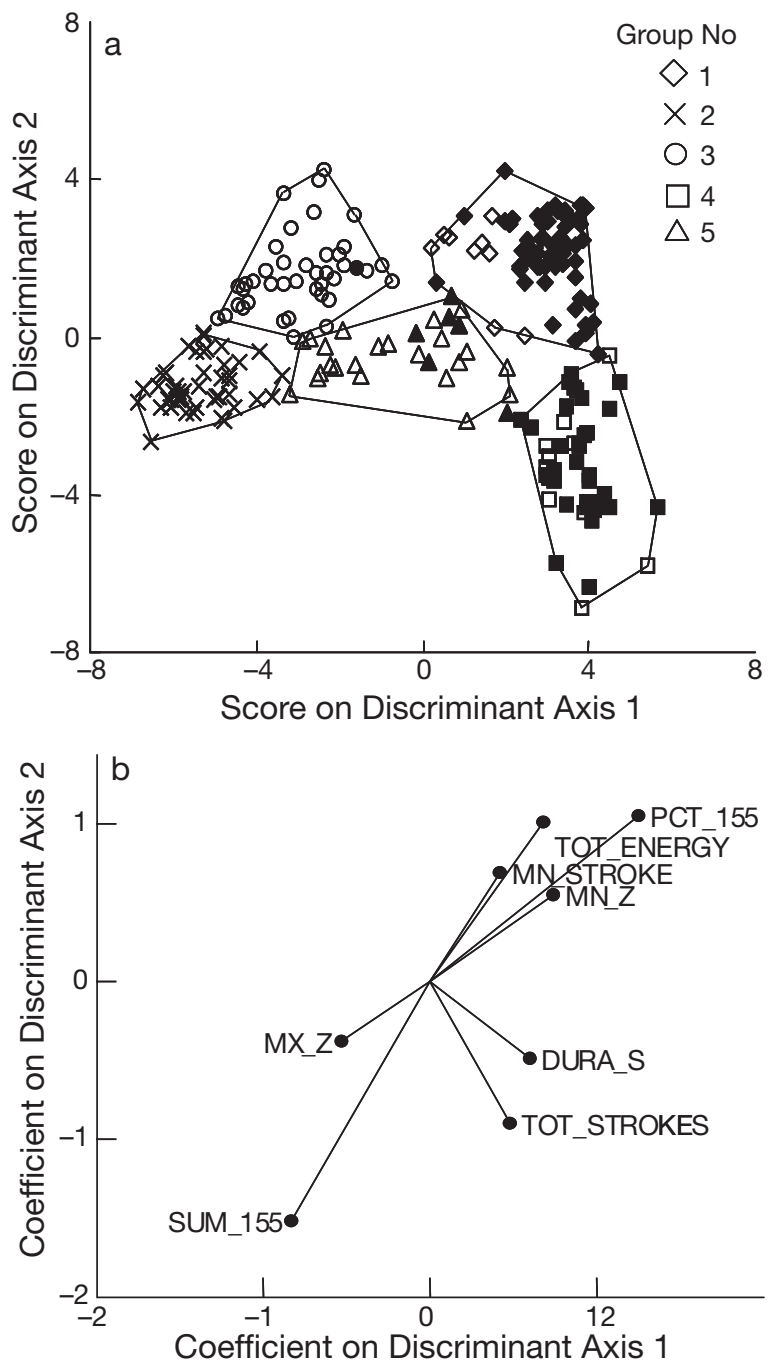

Fig. 3. Leptonychotes weddellii. Discriminant analysis using 5 dive groups that were identified by a $k$-means cluster analysis. (a) View of the discriminant scores for Discriminant Axes 1 and 2. Points represent individual dives, and symbols identify dive groups. Filled symbols indicate dives in which prey were recorded on the video record. (b) Vector plot of standardized canonical coefficients for Discriminant Axes 1 and 2. Only those coefficients identified as important in the discrimination are in-cluded. See Table 2 for abbreviations

Table 3. Leptonychotes weddellii. Jack-knife classification for dives using discriminant analysis on 18 variables for the 5-group cluster analysis

\begin{tabular}{|c|c|c|c|c|c|c|c|c|}
\hline Cluster & $\begin{array}{c}\text { No. } \\
\text { of } \\
\text { dives }\end{array}$ & $\begin{array}{l}\text { Dives } \\
\text { with prey } \\
\text { encoun- } \\
\text { tered }\end{array}$ & $\begin{array}{l}\overline{\text { Group }} \\
1\end{array}$ & $\begin{array}{c}\text { Jack-kni } \\
\text { Group } \\
2\end{array}$ & $\begin{array}{l}\text { ife class } \\
\text { Group } \\
\quad 3\end{array}$ & $\begin{array}{c}\text { ification } \\
\text { Group } \\
4\end{array}$ & $\overline{\text { Group }}$ & $\begin{array}{c}\text { Jack- } \\
\text { knife } \\
\text { classifi- } \\
\text { cation \% }\end{array}$ \\
\hline 1 & 44 & 33 & 42 & 0 & 0 & 2 & 0 & 96 \\
\hline 2 & 46 & 0 & 0 & 43 & 1 & 0 & 2 & 93 \\
\hline 3 & 41 & 1 & 0 & 2 & 38 & 0 & 1 & 93 \\
\hline 4 & 74 & 61 & 1 & 0 & 1 & 71 & 1 & 95 \\
\hline 5 & 29 & 6 & 2 & 1 & 0 & 0 & 26 & 90 \\
\hline
\end{tabular}


Table 4. Leptonychotes weddellii. Standardized canonical coefficients for all dive descriptors included in the stepwise discriminant function analysis. Coefficients and dive descriptors in bold are those which contributed most to the separation according to the discriminant analysis (DA)

\begin{tabular}{|c|c|c|}
\hline Descriptor & DA1 & DA2 \\
\hline \% Dive below silverfish depth & 1.25 & 1.05 \\
\hline Time below silverfish depth (s) & -0.83 & -1.52 \\
\hline Mean depth (m) & 0.74 & 0.55 \\
\hline Total energetic cost $\left(\mathrm{ml} \mathrm{O} \mathbf{~ k g}^{-1}\right)$ & 0.68 & 1.01 \\
\hline Dive duration (min) & 0.60 & -0.49 \\
\hline Maximum depth (m) & -0.53 & -0.38 \\
\hline Total number of strokes (strokes) & 0.48 & -0.90 \\
\hline Mean stroking rate $\left(\right.$ strokes $\left.\mathrm{s}^{-1}\right)$ & 0.42 & 0.69 \\
\hline Speed variability & -0.22 & 0.00 \\
\hline Total distance $(\mathrm{m})$ & 0.19 & 0.35 \\
\hline Maximum speed $\left(\mathrm{m} \mathrm{s}^{-1}\right)$ & 0.17 & -0.36 \\
\hline \% Dive gliding & -0.16 & -0.29 \\
\hline Depth variability & 0.13 & 0.14 \\
\hline Energy rate $\left(\mathrm{ml} \mathrm{O}_{2} \mathrm{~kg}^{-1} \mathrm{~min}^{-1}\right)$ & -0.11 & -0.06 \\
\hline Mean speed $\left(\mathrm{m} \mathrm{s}^{-1}\right)$ & -0.10 & 0.03 \\
\hline Maximum stroking rate $\left(\right.$ strokes $\mathrm{s}^{-1}$ ) & -0.09 & 0.21 \\
\hline Sum time gliding (s) & -0.07 & -0.18 \\
\hline Stroking rate variability & 0.02 & 0.37 \\
\hline
\end{tabular}

values for 7 of the 8 important dive descriptors (as determined by the discriminant analysis) were greatest for Group 1 dives (Table 5). During these dives, seals reached the greatest mean and maximum depths and spent the most time at depths where silverfish were expected to be present (deeper than $155 \mathrm{~m}$ - the mean minimum depth of all silverfish encounters in the current study). They also had the longest total dive duration and contained the greatest number of total strokes, resulting in the highest energetic cost of any dive type. The estimated total-available-body-oxygen store was approximately $67 \mathrm{ml} \mathrm{O}_{2} \mathrm{~kg}^{-1}$ (Kooyman 1989). This means the energetic cost of Group 1 dives generally exceeded the estimated available oxygen stores (Table 5) and is an indication that the seals may have relied on anaerobic metabolism. Average flipper stroke rate was the only discriminating variable that was not the highest for Group 1 dives. Successful Group 1 dives had a similar number of prey encounters $(7.8 \pm 0.9$ mean $\pm \mathrm{SE})$ as Group 5 dives, but contained fewer prey encounters than Group 4 dives.

In Group 4 dives, average values for 6 of the 8 important dive descriptors were between those of Groups 1 and 5 (Table 5). These dives were relatively deep, but shallower (by $8.0 \%$ ) than Group 1 dives. Time spent at depths where silverfish were expected was also slightly less than in Group 1 dives. However, these dives were deeper than Group 5 dives (by $48.0 \%$ ). Although they were similar in duration to Group 5 dives, Group 4 dives were the shortest of the 3 foraging dive types. They had the highest stroking rate, which resulted in a

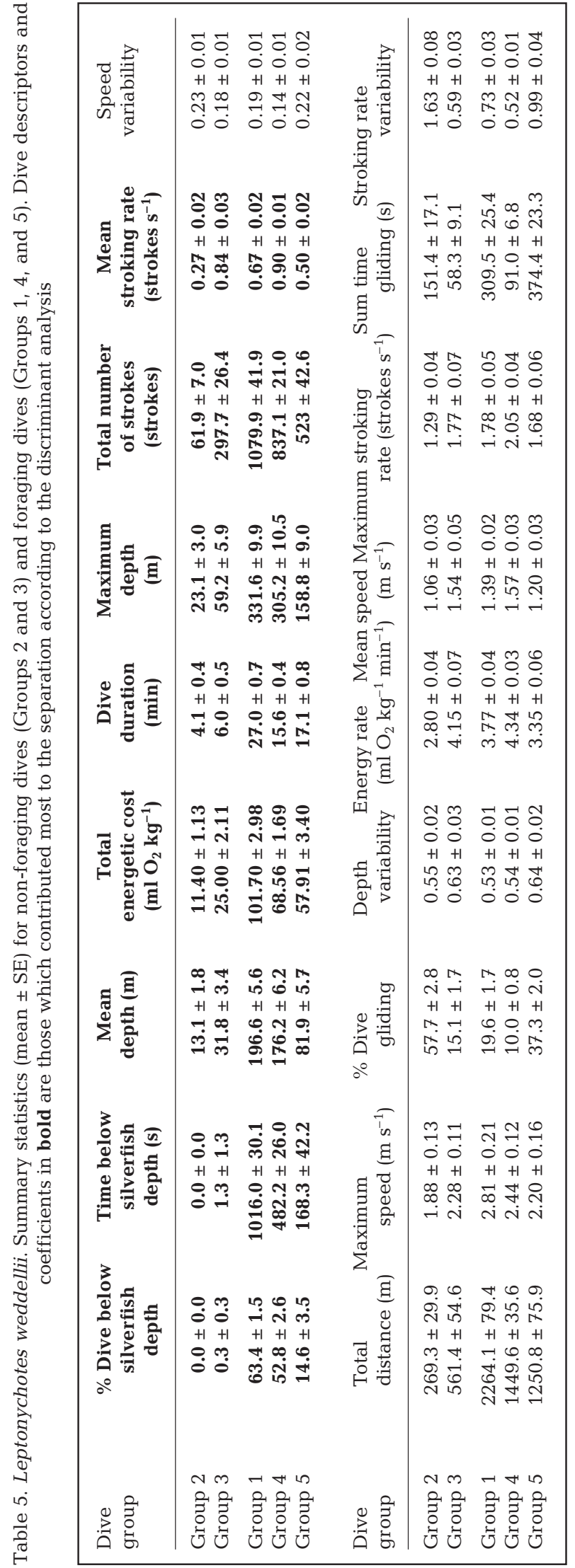


noticeably higher number of total strokes than Group 5 dives. However, they were still characterized by fewer total strokes than Group 1 dives. The shorter duration and decreased number of strokes during Group 4 dives, compared to Group 1, resulted in a lower total energetic cost. The average estimated energetic cost of Group 4 dives was within the available oxygen limits of Weddell seals (Table 5), which suggests they were not relying on anaerobic metabolism. Successful Group 4 dives contained the highest number of prey encounters $(16.5 \pm 1.3)$ of any foraging group.

Average values for 7 of the 8 important dive descriptors were lowest for Group 5 foraging dives (Table 5). They were the shallowest of all foraging dive types and the seals spent the least amount of time below depths where silverfish were expected. Group 5 dives were only slightly longer in duration than Group 4, but were much shorter than Group 1 dives. Despite the similarities in duration between Groups 4 and 5, Group 5 dives showed a noticeably lower flipper stroke rate, which resulted in the lowest number of total strokes for any foraging group. This also resulted in a much lower energetic cost than Group 4 dives, which means seals expended the least amount of energy when foraging during Group 5 dives (Table 5). Successful Group 5 dives contained a similar number of prey encounters as Group 1 dives, but there was greater variability $(7.7 \pm$ 2.6). The 3 foraging dive types were given descriptive names based on their depth and energetic cost; Group 1 dives were deep anaerobic foraging behavior DAnD, Group 4 dives were deep aerobic foraging behavior $\mathrm{DAD}$, and Group 5 dives were shallow aerobic behavior ShAD.

\section{Geographic variability}

Weddell seals foraged at 3 different geographic locations within McMurdo Sound (Fig. 1) and this had a significant effect (Pearson's chi-square $=70.0, \mathrm{p}<$ 0.001 ) on the frequency of the 3 foraging dive types (Table 6, Fig. 4). Standardized deviates showed that seals performed significantly more DAnD (Group 1;

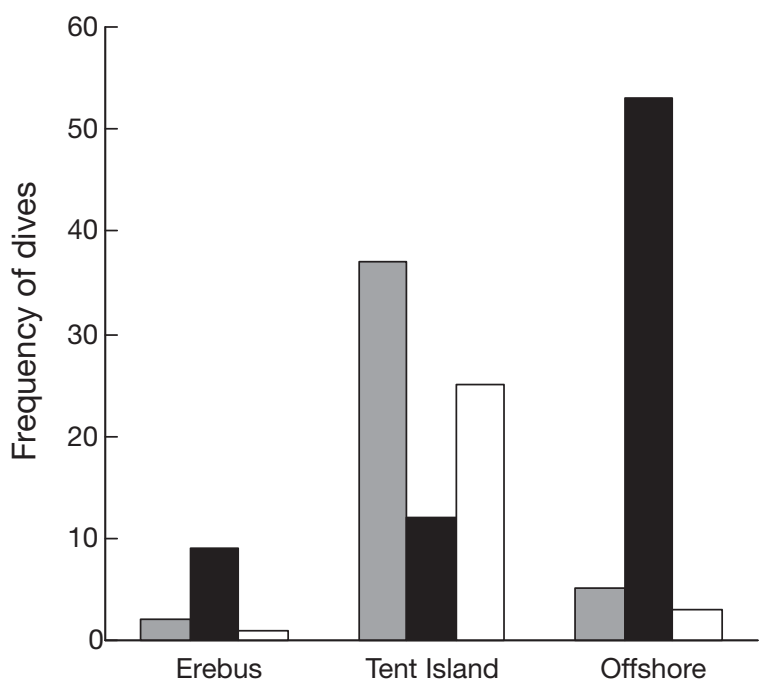

Fig. 4. Leptonychotes weddellii. The distribution of foraging dive types was significantly different at the 3 geographic regions within McMurdo Sound, Antarctica (Pearson's chisquare $=70.0, \mathrm{p}<0.001)$. Bars are filled according to type of foraging dive. Group 1, grey; Group 4, black; Group 5, white

$\mathrm{N}=37$ ) and ShAD (Group 5; $\mathrm{N}=25$ ) along the west coast of Tent Island (shallow water), while performing significantly fewer DAD (Group 4; N = 12). The opposite was true for the 2 seals diving offshore in McMurdo Sound (deep water). In this location, seals made significantly more DAD $(\mathrm{N}=53)$ and significantly fewer DnAD $(\mathrm{N}=5)$ and $\operatorname{ShAD}(\mathrm{N}=3)$. Observed values were not significantly different from expected values for the seals diving near the Erebus Ice Tongue (deep water), but it is worth noting that $\operatorname{DAD}(\mathrm{N}=9)$ were more abundant than DnAD $(\mathrm{N}=2)$ and $\operatorname{ShAD}(\mathrm{N}=1)$. This was similar to the pattern observed at the offshore breathing holes (Table 6).

\section{DISCUSSION}

Free-ranging Weddell seals in McMurdo Sound use a range of foraging dives to locate prey. Three distinct foraging groups were identified in the present study

Table 6. Leptonychotes weddellii. Contingency table analysis. There were significant differences $(p<0.001)$ in the distribution of dive types at the 3 different regions. Standardized deviates were used to determine whether and how expected frequencies differed from observed frequencies. Bold standardized deviates indicate which dive types occurred significantly more ( $>1.96)$ or less $(<-1.96)$ frequently than expected by chance

\begin{tabular}{|c|c|c|c|c|c|c|c|c|c|}
\hline \multirow{2}{*}{$\begin{array}{l}\text { Dive } \\
\text { group }\end{array}$} & \multicolumn{3}{|c|}{- Observed frequency -} & \multicolumn{3}{|c|}{ Expected frequency } & \multicolumn{3}{|c|}{ - Standardized deviates } \\
\hline & Erebus & Tent Island & Offshore & Erebus & Tent Island & Offshore & Erebus & Tent Island & Offshore \\
\hline 1 & 2 & 37 & 5 & 3.6 & 22.1 & 18.3 & -0.8 & 3.2 & -3.1 \\
\hline 4 & 9 & 12 & 53 & 6.0 & 37.3 & 30.7 & 1.2 & -4.1 & 4.0 \\
\hline 5 & 1 & 25 & 3 & 2.4 & 14.6 & 12.0 & -0.9 & 2.7 & -2.6 \\
\hline
\end{tabular}


and the frequency at which these groups were used varied with location. The dominant type of foraging dives performed at each location appeared to be determined by the preferred depth of silverfish, the main prey item of Weddell seals in McMurdo Sound (Castellini et al. 1992, Burns et al. 1998, Davis et al. 1999), and by bathymetry. Silverfish constituted $98.9 \%$ of the seals' diet in the current study and encounters with silverfish occurred between $192.1 \pm 8.0 \mathrm{~m}$ and $318.4 \pm$ $6.4 \mathrm{~m}$ (mean minimum and maximum depth, respectively $\pm \mathrm{SE})$.

Seals diving in the shallow coastal waters at Tent Island used more deep anaerobic foraging dives (Group 1) than seals diving in deeper waters offshore and near the Erebus Ice Tongue. The video record showed that $75 \%$ of deep anaerobic dives contained at least 1 prey encounter and seals averaged close to 8 prey encounters per successful dive. The majority of encounters were with silverfish $(96.1 \%)$, but a small number of benthic prey encounters $(3.5 \%)$ was also observed. All benthic encounters $(n=6)$ occurred along the coastline of Tent Island. Seals in this region swam along the continental slope, as evidenced by the presence of the sea floor on the video record, while traveling to the depths where silverfish typically occur. Therefore, the small number of benthic encounters was most likely the result of seals feeding opportunistically as they swam to and from deeper waters.

Mitani et al. (2004) previously reported that Weddell seals diving along the coastline of an island were forced to travel farther horizontally to find and forage in patches of silverfish. Similarly, we believe the bathymetry at Tent Island was responsible for the increased frequency of deep anaerobic dives at the coast. To test this hypothesis, we compared the 3 locations for differences in the depth and elapsed time to the first silverfish encounter. Silverfish were expected to be found at the same depth in all 3 locations, but were predicted to be encountered significantly later along the coastline of Tent Island, since the seals had to travel farther horizontally to reach the same depths. No significant differences were found among the 3 locations in the depth of the first silverfish encounter (ANOVA $F_{2,91}=2.2, \mathrm{p}=0.114$ ), but there were significant differences in the time of the first encounter (ANOVA; $F_{2,91}=50.7, \mathrm{p}<0.001$ ). Post hoc comparisons using Bonferroni corrections showed that the seals encountered the first silverfish in a dive significantly $(p<0.05)$ later along the coast of Tent Island $(10.6 \pm$ 0.5 min [mean $\pm \mathrm{SE}]$ ) than they did near the Erebus Ice Tongue $(6.5 \pm 0.9 \mathrm{~min})$ or at the offshore location $(5.8 \pm$ $0.2 \mathrm{~min}$ ). This resulted in longer dive durations, greater distances traveled, and higher energetic costs characteristic of deep anaerobic dives, and explains the presence of more deep anaerobic dives originating from the coastline. There was only a small number of deep anaerobic dives over deeper water and the dives that did occur in these locations may have resulted from the seals' inability to initially locate prey, causing the seals to forage more extensively.

Seals diving at Tent Island also performed a greater number of shallow aerobic foraging dives (Group 5) than seals diving at offshore breathing holes. The video record showed that $>20 \%$ of shallow aerobic foraging dives contained at least 1 prey encounter. One benthic fish encounter occurred along the coast of Tent Island, but the majority of encounters were with silverfish $(98.1 \%)$. Although the percentage of successful dives was less for shallow aerobic dives than it was for deep aerobic and deep anaerobic dives, the success rate of shallow aerobic dives was similar to that of deep anaerobic dives ( 8 encounters per dive). This suggests that shallow aerobic dives were not just incidental encounters but represent a third type of foraging behavior. The average depth of the first silverfish encounter during shallow aerobic dives (142.3 \pm $13.9 \mathrm{~m}$ ) was significantly shallower (ANOVA; $F_{2,91}=$ $19.5, \mathrm{p}<0.001)$ than in deep anaerobic $(309.1 \pm 10.7 \mathrm{~m})$ and deep aerobic $(306.3 \pm 7.6 \mathrm{~m})$ dives. The shorter durations, lower stroking rates, and shallower depths of prey encounters associated with this type of foraging behavior could indicate an energy-saving foraging strategy in which the seals were exploiting shallow schools of silverfish. If capture rates are similar for deep anaerobic and shallow aerobic dives, the ratio of energy gained to energy expended (i.e. net energy gain) will be much higher for shallow aerobic dives.

Although shallow aerobic foraging dives were performed at a higher frequency at Tent Island, the percentage of successful shallow aerobic dives $(10 \%)$ was lower at this location than it was at the 2 offshore locations. The 3 shallow aerobic dives that occurred at offshore breathing holes all resulted in silverfish encounters. Only 1 shallow aerobic dive occurred near the Erebus Ice Tongue and it was unsuccessful. The successful shallow aerobic dives at Tent Island had fewer encounters than the successful dives at offshore breathing holes $(3.7 \pm 2.2$ vs. $11.7 \pm 3.5$ encounters per dive, respectively). Thus, shallow aerobic diving appears to be a less successful foraging strategy at Tent Island. However, shallow aerobic foraging is still an energy efficient strategy if the seals are able to capture prey and the increased frequency of shallow aerobic dives at Tent Island suggests that seals in this location were attempting to exploit shallow schools of prey more often than the seals foraging offshore. However, the lower success rate of shallow aerobic dives at Tent Island indicates that shallow prey may be less available in this region, which could explain the high frequency of deep anaerobic dives. In other words, when 
seals were unable to locate shallow schools of prey along the coast, they had to expend more time and energy traveling to depths where silverfish were typically more abundant. Future analysis of the sequence of dive types could reveal more about the function of shallow aerobic foraging behavior.

Seals diving offshore and near the Erebus Ice Tongue used more deep aerobic foraging dives (Group 4) than seals diving along the coastline. The video record showed that $>82 \%$ of deep aerobic dives contained at least 1 prey encounter and that silverfish constituted $98.9 \%$ of the seals' diet during these dives. Deep aerobic dives were the most successful foraging group, averaging $>16$ prey encounters per dive. When seals foraged from breathing holes over deep water (ca. $500 \mathrm{~m}$ ), they were not forced to follow the continental slope and were able to spend less time, travel a shorter distance, and expend less energy to reach the depths where silverfish typically occurred. This explains why the first silverfish encounter in a dive occurred significantly earlier at both offshore locations than it did at Tent Island.

Results from the current study show similarities with prior dive classifications for Weddell seals, but comparisons with these studies also indicate that seals use a wider range of foraging dive types to locate prey than previously thought. Based on time and depth statistics, deep aerobic dives were similar to the foraging dives identified in 3 previous classification studies (Kooyman 1968, Schreer \& Testa 1996, Davis et al. 2003). Deep anaerobic dives were also similar in depth and duration to the benthic foraging dives identified previously by Schreer \& Testa (1996), but evidence from the video record suggests that these dives were not indicative of benthic foraging. There were very few benthic encounters observed and seals did not always reach the sea floor during deep anaerobic dives. Instead, Weddell seals appear to use these dives to travel to silverfish depths from breathing holes along the coastline or to forage more extensively offshore when prey are difficult to find. Shallow aerobic dives were similar in depth and duration to the Type 3 dives identified by Schreer \& Testa (1996), but in their study a foraging function was not proposed for this group; they hypothesized that the seals either were following the slope of the sea floor as they descended or were exploring the area for future foraging opportunities. The video record showed that the bottom was visible in all but 1 dive at Tent Island, which might suggest that seals were following the coastal slope in this region. However, the sea floor was never observed during the shallow aerobic dives at the 2 offshore locations and seals successfully encountered prey at a relatively high frequency during these dives. This indicates that shallow aerobic dives are a type of foraging behavior that had previously not been identified as such.

In summary, 3 groups of foraging dives were identified for free-ranging Weddell seals. The distribution of foraging groups varied among locations and the type of dives performed at each location was determined by the depth of silverfish and bathymetric variability within McMurdo Sound. The proportion of successful dives and the average number of encounters per successful dive varied among groups and locations. Seals diving along the coast used more deep anaerobic and shallow aerobic dives. Deep anaerobic dives require more energy than shallow aerobic dives, but the percentage of successful dives was higher for deep anaerobic dives. For seals foraging along the coast, there may be an interesting trade-off between expending less energy to forage at depths where silverfish are less likely to be encountered and expending more energy to forage at depths where the opportunities for locating silverfish are greater. This trade-off could be especially important, as Weddell seals congregate and forage along coastlines during the summer breeding season (Kooyman 1968, Castellini et al. 1992, Testa 1994), a time when differences in foraging efficiency could be particularly important. When seals foraged away from the coast they used more deep aerobic dives. These dives required less time and energy to travel to silverfish depths than deep anaerobic dives and resulted in more silverfish encounters. This suggests that foraging offshore using deep aerobic dives is a very efficient strategy. However, another important trade-off could exist between foraging close to Tent Island, where the seals' chances of breeding successfully are higher, and expending time and energy to travel offshore, where foraging is more efficient.

Identification of a range of foraging behaviors shows how Weddell seals deal with the trade-offs between energetic cost of traveling to prey, likelihood of encountering prey at certain depths, and the need to remain near breathing holes along coastlines to breed. Comparisons with Weddell seals diving in other areas of Antarctica could provide further information about how foraging strategies change according to prey type and bathymetry.

Acknowledgements. This research was funded by the National Science Foundation, Office of Polar Programs (OPP9909422). Additional financial support was provided by the Nancy Lee and Perry R. Bass Endowment at the University of Texas Marine Science Institute. Thank you to D. Calkins, W. Hagey, M. Horning, S. Kanatous, M. Rutishauser, R. Watson, and J. Purdy for their work in the field. Special thanks to W. Hagey for his invaluable role in the development of the equipment and to M. Davis and M. Rutishauser, who spent many hours examining video footage. Finally, thank you to the members of my lab, particularly A. F. Ojanguren, who gave thoughtful comments and asked insightful questions throughout the development of this manuscript. 


\section{LITERATURE CITED}

Blackwell SB, Haverl CA, LeBoeuf BJ, Costa DP (1999) A method for calibrating swim speed recorders. Mar Mamm Sci 15:894-905

Block BA (2005) Physiological ecology in the 21st Century: advancements in biologging science. Integr Comp Biol 45:305-320

Boyd IL, Staniland IJ, Martin AR (2002) Distribution of foraging by female Antarctic fur seals. Mar Ecol Prog Ser 242: 285-294

Burns JM, Trumble SJ, Castellini MA, Testa JW (1998) The diet of Weddell seals in McMurdo Sound, Antarctica as determined from scat collections and stable isotope analysis. Polar Biol 19:272-282

Castellini MA, Davis RW, Kooyman GL (1992) Annual cycles of diving behavior and ecology of the Weddell seal. Bull Scripps Inst Oceanogr 28:1-54

Crocker DE, LeBoeuf BJ, Costa DP (1997) Drift diving in female northern elephant seals: implications for food processing. Can J Zool 75:27-39

Culik BM, Bannasch R, Wilson RP (1994) External devices on penguins: How important is shape? Mar Biol 118:353-357

Davis RW, Fuiman LA, Williams TM, Collier SO and others (1999) Hunting behavior of a marine mammal beneath the Antarctic fast ice. Science 283:993-996

Davis RW, Fuiman LA, Williams TM, Horning M, Hagey W (2003) Classification of Weddell seal dives based on 3-dimensional movements and video-recorded observations. Mar Ecol Prog Ser 264:109-122

> Dearborn JH (1965) Food of Weddell seals at McMurdo Sound, Antarctica. J Mammal 46:37-43

Fedak M, Lovell P, McConnell B, Hunter C (2002) Overcoming the constraints of long range radio telemetry from animals: getting more useful data from smaller packages. Integr Comp Biol 42:3-10

Fuiman LA, Davis RW, Williams TM (2002) Behavior of midwater fishes under the Antarctic ice: observations by a predator. Mar Biol 140:815-822

Fuiman LA, Madden KM, Williams TM, Davis RW (2007) Structure of foraging dives by Weddell seals at an isolated hole in the Antarctic fast-ice environment. Deep-Sea Res II 54:270-289

Harcourt RG, Hindell MA, Bell DG, Waas JR (2000) Threedimensional dive profiles of free-ranging Weddell seals. Polar Biol 23:479-487

Hinde RA (1982) Ethology: its nature and relations to other sciences. Oxford University Press, Oxford

Hindell MA, Slip DJ, Burton HR (1991) The diving behaviour of adult male and female Southern elephant seals, Mirounga leonine (Pinnipedia: Phocidae). Aust J Zool 39: 595-619

> Hindell MA, Harcourt R, Waas JR, Thompson D (2002) Finescale three-dimensional spatial use by diving, lactating female Weddell seals Leptonychotes weddellii. Mar Ecol Prog Ser 242:275-284

> Hooker SK, Boyd IL, Jessop M, Cox O, Blackwell J, Boveng PL, Bengston JL (2002) Monitoring the prey-field of marine predators: combining digital imaging with data logging tags. Mar Mamm Sci 18:680-687

> Hume F, Hindell MA, Pemberton D, Gales R (2004) Spatial and temporal variation in the diet of a high trophic level predator, the Australian fur seal (Arctocephalus pusillus doriferus). Mar Biol 144:407-415

Johnson MP, Tyack PL (2003) A digital acoustic recording tag for measuring the response of wild marine mammals to sound. IEEE J Oceanic Eng 28:3-12
Johnson MP, Madsen PT, Zimmer WMX, de Soto NA, Tyack PL (2004) Beaked whales echolocate on prey. Proc R Soc Lond B Biol Sci 271:S383-S386

Kooyman GL (1968) An analysis of some behavioral and physiological characteristics related to diving in the Weddell seal. In: Schmitt WL, Llano GA (eds) Antarctic Research Series, Vol. 11, Biology of the Antarctic Seas III. American Geophysical Union, Washington, DC, p 227-261.

Kooyman GL (1981) Weddell seal: consummate diver. Cambridge University Press, Cambridge

Kooyman GL (1989) Diverse divers: physiology and behavior. Springer-Verlag, Berlin

Kooyman GL (2004) Genesis and evolution of bio-logging devices: 1963-2002. Mem Natl Inst Polar Res 58(Spec Issue):15-22

> Lake S, Burton H, van den Hoff J (2003) Regional, temporal and fine-scale spatial variation in Weddell seal diet at four coastal locations in east Antarctica. Mar Ecol Prog Ser 254:293-305

Lavigne DM, Bernholz CD, Ronald K (1977) Functional aspects of pinniped vision. In: Harrison RJ (ed) Functional anatomy of marine mammals. Academic Press, New York, p 135-174

LeBoeuf BJ, Naito Y, Asaga T, Crocker D, Costa DP (1992) Swim speed in a female northern elephant seal: metabolic and foraging implications. Can J Zool 70:786-795

Lehner PN (1996) Handbook of ethological methods, 2nd edn. Cambridge University Press, Cambridge

Lesage V, Hammill MO, Kovacs KM (1999) Functional classification of harbor seal (Phoca vitulina) dives using depth profiles, swimming velocity, and an index of foraging success. Can J Zool 66:149-178

Madsen PT, Johnson MP, de Soto NA, Zimmer WMX, Tyack PL (2005) Biosonar performance of foraging beaked whales (Mesoplodon densirostris). J Exp Biol 208:181-194

Manly BFJ (2005) Multivariate statistical methods: a primer, 3rd edn. Chapman \& Hall/CRC, Boca Raton, FL

Marshall GJ (1998) Crittercam: an animal-borne imaging and data logging system. Mar Technol Soc J 32:11-17

Martin P, Bateson P (1993) Measuring behaviour: an introductory guide, 2nd edn. Cambridge University Press, Cambridge

Mitani Y, Sato K, Ito S, Cameron MF, Siniff DB, Naito Y (2003) A method for reconstructing three-dimensional dive profiles of marine mammals using geomagnetic intensity data: results from two lactating Weddell seals. Polar Biol 26:311-317

> Mitani Y, Watanabe Y, Sato K, Cameron MF, Naito Y (2004) $3 \mathrm{D}$ diving behavior of Weddell seals with respect to prey accessibility and abundance. Mar Ecol Prog Ser 281: $275-281$

> Plötz J, Bornemann H, Knust R, Schröder A, Bester M (2001) Foraging behaviour of Weddell seals, and its ecological implications. Polar Biol 24:901-909

Sato K, Mitani Y, Cameron MF, Siniff DB, Watanabe Y, Naito $Y$ (2002) Deep foraging dives in relation to the energy depletion of Weddell seal (Leptonychotes weddellii) mothers during lactation. Polar Biol 25:696-702

Schreer JF, Testa JW (1996) Classification of Weddell seal diving behavior. Mar Mamm Sci 12:227-250

Simpkins MA, Kelly BP, Wartzok D (2001) Three-dimensional diving behaviors of ringed seals (Phoca hispida). Mar Mamm Sci 17:909-925

Testa JW (1994) Over-winter movements and diving behavior of female Weddell seals (Leptonychotes weddellii) in the southwestern Ross Sea, Antarctica. Can J Zool 72: $1700-1710$ 
Testa JW, Siniff DB, Ross MJ, Winter JD (1985) Weddell sealAntarctic cod interactions in McMurdo Sound, Antarctica. In: Siegfried WR, Cody PR, Laws RM (eds) Antarctica Nutrient cycles and food webs. Springer-Verlag, New York, p 561-565

Tremblay Y, Cherel Y (2000) Benthic and pelagic dives: a new foraging behavior in rockhopper penguins. Mar Ecol Prog Ser 204:257-267

$>$ Wartzok D, Sayegh S, Stone H, Barchak J, Barnes W (1992) Acoustic tracking system for monitoring under-ice movements of polar seals. J Acoust Soc Am 92:682-687

Watanabe Y, Mitani Y, Sato K, Cameron MF, Naito Y (2003) Dive depths of Weddell seals in relation to vertical prey

Editorial responsibility: Rory Wilson,

Swansea, UK distribution as estimated by image data. Mar Ecol Prog Ser 252:283-288

Williams TM, Fuiman LA, Horning M, Davis RW (2004) The cost of foraging by a marine predator, the Weddell seal (Leptonychotes weddellii): pricing by the stroke. J Exp Biol 207:973-982

Wilson RP, Grant WS, Duffy DC (1986) Recording devices on free-ranging marine animals: does measurement affect foraging performance? Ecology 67:1091-1093

Wilson RP, Wilson MP, Link R, Mempel H, Adams NJ (1991) Determination of movements of African penguins, Spheniscus demersus, using a compass system: dead reckoning may be an alternative to telemetry. J Exp Biol 157:557-564

Submitted: August 30, 2007; Accepted: January 8, 2008 Proofs received from author(s): July 18, 2008 